This is an electronic reprint of the original article. This reprint may differ from the original in pagination and typographic detail.

Author(s): Collin, Kaija; Paloniemi, Susanna; Herranen, Sanna

Title: $\quad$ INPROF : promoting teamwork processes and interprofessional collaboration in emergency work (2010-2012)

Year: $\quad 2015$

Version:

Please cite the original version:

Collin, K., Paloniemi, S., \& Herranen, S. (2015). INPROF : promoting teamwork processes and interprofessional collaboration in emergency work (2010-2012). Studies in Continuing Education, 37(2), 142-156. https://doi.org/10.1080/0158037X.2014.997199

All material supplied via JYX is protected by copyright and other intellectual property rights, and duplication or sale of all or part of any of the repository collections is not permitted, except that material may be duplicated by you for your research use or educational purposes in electronic or print form. You must obtain permission for any other use. Electronic or print copies may not be offered, whether for sale or otherwise to anyone who is not an authorised user. 


\title{
INPROF - Promoting Teamwork Processes and Interprofessional Collaboration in Emergency Work (2010-2012)
}

\begin{abstract}
This paper summarises the findings of a research project on interprofessional collaboration in the emergency unit of a major Finnish hospital. The findings are discussed through a broad conceptual framework which involves work process knowledge and interprofessional collaboration. The project, carried out from 2010-2012, investigated different forms of, prerequisites for, and barriers to, collaboration, and the aim was to develop the work together with staff at the unit. An ethnographically informed research strategy was utilised, with observations and interviews as the main data collection methods. On the whole, collaboration in the emergency unit was found to function rather well; i.e. patients receive good-quality treatment within the ideal time frame. We found that in the unit, the most suitable form for the majority of collaborations is multi-professional collaboration, in which professionals exchange information but still adhere strongly to their own professional groups. More interprofessional collaboration is required particularly in leadership and management, to create further improvements in i) the coordination of work as a whole, and ii) the implementation of organisational changes and new professional roles. Obstacles to interprofessional collaboration in particular appear to be: i) diverging professional values and core professional identities, and ii) power relations that create inequality.
\end{abstract}

Keywords: interprofessional collaboration, work process knowledge, ethnography, emergency work, workplace learning.

\section{Introduction}

Contemporary emergency work is a fragmented field. Responsibility for work has often lain in the hands of medical specialities (surgery, neurology, internal medicine etc.), and comprehensive patient care is usually challenging and time-consuming. Holistic patient care, a customer-oriented approach, cost-effectiveness and increased quality of care all contribute to the need, however, for interprofessional collaboration (Baker, Day and Salas 2006; D’Amour, Ferrada-Videla, San MartínRodríguez and Beaulieu 2005; Pollard, Sellman and Senior 2005). Emergency work can be seen as an environment in which interprofessional teamwork and learning are essential to securing and developing patient safety and effective practice (McCallin 2001; Nembhard and Edmondson 2006).

The requirements and challenges within interprofessional collaboration vary depending on the operational environment. The environment (e.g. emergency duty) is challenged continuously by changes in the composition of care groups and employees doing three-shift and emergency-natured work (Rekola, Isoherranen and Koponen 2005). In everyday critical and busy situations, all workers need to know their duties and be able to trust each other's competence. At times, collaboration between experts in different specialities can be dynamic, but it is often situation-specific. It is also often difficult to find time and space for interprofessional collaboration and discussion. Therefore, it is important that everyone understands work processes in the same way and that communication between people is fluent (Pullon 2008). Further, organisational structures constitute a challenge in that they do not support shared knowledge and a joint-operating model. The conventional medical model applauds autonomy and individualism and is a top-down or hierarchical control model, focusing on technical expertise and neglecting the non-technical capabilities that are central to interprofessional work (see Lingard, Espin, Evans and Hawryluck 2004).

Despite enduring academic discussions about multi-professionalism, teamwork and the effectiveness of health care work, we still know relatively little about functional work between 
professional groups (Pollard, Sellman and Senior 2005) and collaborative processes in emergency work (Lemieux-Charles and McGuire 2006). Further, although the challenges within, and constraints upon, interprofessional collaboration in health care have been analyzed (e.g. Ramanujam and Rousseau 2006), only a small number of studies have concentrated on operational processes (Collin, Paloniemi and Mecklin 2010). This research aims to contribute towards filling these gaps.

This paper summarises and discusses the main findings of a research project on interprofessional collaboration at the emergency unit of a major Finnish hospital. We will utilise a broad conceptual framework which is informed, firstly, by work process knowledge (see Boreham 2004). The idea of work process knowledge suggests that all employees should understand their work in a holistic way, as a series of parts in one set of processes. It manifests in active and practical knowledge embedded in work practices and is most typically used in different kinds of problem-solving situations. Secondly, interprofessional collaboration is framed here as an ideal, denoting a combination of know-how and expertise from different professional domains in a work community or a working group (Housley 2003). In this paper, we will offer a critical investigation of these two concepts. Our focus on interprofessional collaboration derives from a socio-cultural understanding of learning (Wenger 1998). As many of the obstacles for learning in organisations (including health care organisations) have been found to be social in nature (Collin, Paloniemi, Virtanen and Eteläpelto 2008), we place a strong emphasis on the participatory nature of learning in work communities.

\section{Promoting teamwork processes and interprofessional collaboration in emergency work - the INPROF research project}

The INPROF research project was conducted during the years 2010-2012 in collaboration with Central Finland Central Hospital and the Department of Education, University of Jyväskylä. The emergency unit in question has been disclosed in research publications, based on a mutual agreement. By working in collaboration with emergency unit staff, the project aimed to investigate both those work processes that function well and those that might need development. The ultimate goal was to develop solutions for promoting interprofessional sharing of expertise in the emergency unit. In the investigation and development of team processes and interprofessional collaboration, issues such as division of work, organising work practices, sharing expertise, learning and interaction were taken into account. Ethnography offered a methodological approach (Hammersley and Atkinson 2007) that allowed the emphasis of collaborative practices and requirements, as well as their possibilities and challenges, within emergency work practices.

More specifically, we asked:

i) What kinds of forms of collaboration exist in the practices of the emergency unit staff?

ii) How do work process knowledge and interprofessional collaboration manifest themselves in the work of the emergency unit staff?

The project was divided into three phases. Firstly, we mapped the central procedures and practices in interprofessional collaboration within the emergency unit. The aim of the first phase was to collaborate with staff to create an understanding of their work practices and developmental needs. Developmental plans and efforts were guided by the idea that improvement evolves from existing good practices, as well as from the recognition of challenges, opportunities and staff needs (e.g. Collin, Valleala, Herranen and Paloniemi 2012). The second phase concentrated on exploring research-based practical solutions to developmental needs. The researchers acted as facilitators and 'mirrors' by introducing research findings on processes that might require development and by arranging forums together with the staff (e.g. development days) to promote mutual discussion on central topics. During this phase of the project, major changes in emergency work actions took place outside of the INPROF activities. Thus, the themes of interest in many of the developmental 
efforts focusing on interprofessional collaboration were defined by the emergency unit staff members themselves.

For the third work phase, we set a goal of building a model of shared expertise that could also be applied in other similar contexts (e.g. in acute care in general). However, during the project, it became evident that this was neither possible nor useful. Due to the nature of emergency work (and hospital work more generally), the context-specific work environments and the fairly short duration of the project, constructing one single model for varying work processes was not seen as feasible. It was not possible to capture the diversity and the multifaceted nature of different work environments and situations with the help of one general collaborative model, especially in such a short time frame; attempts at building such a model would require more long-term research in a given context and, due to the complexity of work environments, the model would be applicable mostly in similar contexts, not necessarily in all work contexts. We argue for more local and context-specific research in order to build an applicable model. This context-specific research should be conducted within various contexts to facilitate the generation of a widely applicable model.

\section{Context and Research Methods}

\section{Emergency work at Central Finland Central Hospital}

At the time of the study, the emergency unit at Central Finland Central Hospital consists of an emergency clinic and an emergency and infection ward (EIW). The number of staff is between 170 and 200, not including itinerants from other hospital units. Since the year 2008, the emergency unit has functioned administratively as an independent unit in the hospital, taking care of primary and special health care on-duty responsibilities in the region. The emergency unit functions in a recently constructed building and in 2011, there were approximately 90,000 patient visits.

The aims of the emergency clinic are: fast and effective diagnosis, commencement of treatment, definition of needs and placement for further treatment. The goal is that at least 80 per cent of patients should be treated within two hours. The unit is divided into two sections: one for primary health care and the other for special health care. The special health care section is divided further into four smaller units for conservative, operative, children's and emergency care (trauma room). In addition, nurses work on a triage system (which is the process of determining the priority of a patient's treatment on the basis of the severity of their condition).

The idea of the $E I W$ is to treat emergency conditions that need longer treatment than that which the emergency clinic provides. Patients are admitted and then sent on to further treatment, or sent home. The aim is for patients to stay in the EIW for no longer than two days. The vast majority of patients are transferred to the EIW from the emergency clinic. Therefore, these two units work in close and continuous collaboration.

Work at the emergency unit is hectic, requiring rapid decision-making and fluency in work processes. In addition, the composition of the care groups is subject to frequent change. The staff needs to take care of patients with various diseases, a goal which requires more ability to answer to patients' needs collaboratively, share expertise, understand work processes as a whole and react quickly in changing situations. Thus, the development of emergency care processes and interprofessional collaboration has been seen as vital in the organisation and more broadly.

\section{Ethnographic approach as a research strategy}


The foci of this study - teamwork processes and interprofessional collaboration - are best approached via methods which enable observations of authentic everyday work practices and interactions. Therefore, our methodological approach was informed by ethnography (Hammersley and Atkinson 2007). Utilising ethnography enabled us to gain a multifaceted understanding of the research context (particularly in phase one), which, as we seek to demonstrate, is also a vital condition for developmental efforts. Later on in phases one and two, participatory planning of developmental actions was implemented in the spirit of collective ethnography: the emergency unit staff and the steering group of the project actualised these development efforts together. Responsibility for communicating the findings was placed on both the researchers and the staff. Ethnography and collective ethnography (Paloniemi and Collin 2010a; Gordon et al. 2006; Sigaud 2008; Woods et al. 2000) not only enable a better understanding of the research context but also facilitate the close investigation of interactions among staff at grass-roots level. Ethnography can also be applied effectively to the hectic work in the emergency unit as it enables quick reactions to changes in the unit when necessary. Collaboration between a total of four researchers was utilised in the project.

Permissions for the research were granted by the ethical boards of both the hospital and the university. Consequently, ethical guidelines for research were followed carefully. The research did not focus on patients during any phase. The emergency unit staff was informed clearly about the research before the field work commenced. Further, during field work observations, the project, its aims and its practices were discussed.

The main data collection devices comprised of observations and interviews. First of all, observations were collected about everyday work in the emergency unit through the researchers' field diaries, and via audio-recorded discussions between staff members themselves and between the researchers and staff in different situations in which interprofessional collaboration may take place. Observational data was also collected via the shadowing of employees. We also utilised various documents as research data (e.g. available statistics, reports and other official documents), as well as making observations in staff meetings. The analysis comprised of various qualitative analytical devices, such as content analysis and thematic analysis (Braun and Clarke 2006). At least two researchers were always present during the data collection, and the data was analysed collaboratively by all the researchers. Methodological choices are explained more thoroughly in the project publications described in Table 1. After the collection and analysis of the research data, we proceeded to develop the work practices of the emergency unit, together with the staff. Thus, our research findings served as a support to developmental efforts.

The following Table 1 presents the phenomena under study during the research project. Further, it describes the reasons why these phenomena were studied and the papers in which the findings are reported more closely.

[Table 1 here]

\section{Findings}

In the project, three forms of collaboration were found in the emergency unit, one of which can be classed as multi-professional and two as interprofessional: i) multi-professional involvement with the chain of treatment, representing the 'traditional' division of work, where all the professional groups realised their established, pre-assigned duties - they worked side by side and delivered information to each other, but still held firmly to their own professional groups, ii) mutual planning of patient care, and iii) treatment of particular patient groups, e.g. substance abusers or psychiatric patients. Each form of collaboration also included particular challenges, for example: deficiencies in 
the flow of information and inconsistent practices (multi-professional work), interaction in rigid hospital hierarchies (planning of care), and orientation and advising of new employees in constantly changing circumstances (treatment of particular patient groups). Our study showed that, although hospitals are challenging contexts for learning, the possibility for learning is present in several ways. We found that individual-level learning is the most common kind of learning in everyday patient care situations. Team learning is, however, more challenging and requires different kinds of boundary-crossing and even the removal of professional boundaries. The role of nurses may be decisive in interprofessional collaboration and learning, especially if they are recognised as having tasks and responsibilities that they perform independently during patient care, as in the example of triage (for further details, see Collin et al. 2012).

During the INPROF research project, the most significant change (unrelated to the research project) in the Central Finland Central Hospital emergency unit was a substantial increase in patient volume. This increase occurred due to the expansion of the regional night-time emergency services, and caused the need for several modifications in the unit's action models. As the change was investigated during the INPROF project, the importance of participation for learning within change was confirmed. Further, participation manifested itself as a more multifaceted phenomenon than it has been considered in previous studies (e.g. López, Peón and Ordás 2006; Bess, Perkins, Cooper and Jones 2011). Employee participation in the change was characterised by connections between organisational and individual levels in terms of i) structures and practices provided by the organisation that facilitated employee participation, such as regular meetings open to the entire staff or open discussions, and ii) the nature of participation within these structures and practices as chosen by individual employees. Participation opportunities for the staff in i) planning and decisionmaking, ii) identity work and iii) training before and during the implementation of new practices were found to be critical terms of individual-level learning opportunities within organisational change. These participation opportunities did not materialise sufficiently in this case and we suggest that these aspects require more attention within the process of executing organisational changes and in organisational development. Although employees were not included in decision-making in the planning of the change, employee participation increased organisation-level learning opportunities in the form of expressing work-related problems (Valleala, Herranen, Collin and Paloniemi, in press).

As part of the above-mentioned organisational change, the role of chief duty nurses (shift-specific leaders of nursing) was modified. The work of chief duty nurses was also studied in this project and was found to comprise of tasks such as coordination, clinical work, advising, problem-solving and motivating colleagues; there were differences, however, between various staff members in their perceptions and undertaking of these duties. The main issues that were found to relate to this newly modified work role focused, firstly, on how the role and tasks of chief duty nurse were perceived by the chief duty nurses themselves on one hand, and how they were viewed by the rest of the work community on the other, e.g. some staff members not entirely understanding or accepting the higher-status nursing role. Secondly, there were discrepancies in practicing chief duty nursing; for instance, the 'amount' of participation in routine clinical work by chief duty nurses, and their diligence in circulating and monitoring the clinic. Thirdly, negotiations of power, both official and unofficial, were found to be a central issue. Our empirical data suggests that the new position could be problematic in terms of gaining the respect of colleagues and that this respect, or a lack of it, may also relate to personal characteristics. Our research showed that negotiations of professional identity amid changes in work roles should be understood not only as individual processes, but also as social negotiations taking place across the entire work community. Further, our study illustrated the complexities involved in the professional identity negotiations by which the new position of chief duty nurses was constructed. For an individual nurse, the challenge arising from alternating between the positions of chief duty nurse and care group nurse relates to finding meaningfulness in the new duties at hand. For the nursing community, the challenge lies in negotiating a legitimate 
position for the new division of work in the context of an emergency clinic (Paloniemi, Valleala, Collin and Herranen, forthcoming).

Figure 1 depicts and summarises the main themes and findings of the INPROF project. Some of the themes were included in the project to begin with, whereas some emerged, in the spirit of ethnography, as the project advanced.

[Figure 1 here]

\section{Discussion}

Overall, the INPROF research project provided new knowledge on operational processes, the collaboration of different professionals, and learning in emergency work (see Pollard, Sellman and Senior 2005; Lemieux-Charles and McGuire 2006) - areas that have, to date, received fairly little attention in research. On the whole, collaboration in the emergency unit was found to function rather well; i.e. patients received good-quality treatment within the ideal time frame (Collin et al. 2012). Many of the operational processes were, however, still taking shape. In the following sections, we will discuss our findings more thoroughly.

\section{Work Process Knowledge}

Previous research has argued that it is vital that all employees should understand their work in a holistic way, as a series of parts in one set of processes (Boreham 2004; Pullon 2008) and that the communication is fluent (Pullon 2008), both of which are conditions that materialised only partly in the unit studied here. We observed that hospital hierarchies (as discussed by Lingard and colleagues, 2004), and divergent administrative bodies in different professional groups (especially those of nursing and medicine) complicated the perception of overall processes in the work. Based on our interpretations, different professional groups have differing understandings of work processes, as has also been noted by Copnell et al. (2003) and Krogstad, Hofoss and Hjortdal (2004). The various professional groups value their own concerns and thus pay attention to different parts of processes. A fairly typical problem from the viewpoint of nurses and secretaries, related to the deficient flow of information and inconsistent practices mentioned earlier, was that of doctors' entries being missing from transfer documents concerning patients' subsequent treatment. These entries, which may seem rather marginal in terms of doctors' work as a whole, are of indispensable importance to nurses and secretaries, who can advance treatment processes on the doctors' behalf.

Decision-making in earlier phases of work processes (e.g. doctors at the emergency clinic deciding to transfer patients to the EIW) is crucial in terms of the success of other actors' overall processes (e.g. staff on the EIW), yet the matter is not straightforward. Patient transfers are an example of an issue that polarises views and reflects the complexity of reconciling different professional opinions and processes: on one hand, the emergency clinic - even in its architectural solutions - aims at the commencement of treatment and at fast transfers to other units; backlogs, therefore, are a major challenge that the clinic attempts to evade. On the other hand, the EIW might already be too full or constantly receive 'wrong' patients, e.g. those in need of more long-term treatment. At the same time, as evidenced by quotes from several staff members in our data ("we're here for patients", "patients are number one priority"), good-quality care and treatment obligation are acknowledged and valued in both units.

Work process knowledge in work communities is seen characteristically as being separate from its actors; as belonging mainly to managers and supervisors and as being subject to external coordination and control (Järvensivu 2007). In practice, this sometimes manifests itself in one 
professional not even attempting to understand the viewpoint of the other professional. A shared perception of overall care processes presupposes discussion and the participation of the entire staff, as well as an understanding of one another's work. In general, understanding of work processes as a whole seems to be relatively congruent among all the professional groups. However, we observed that there were differences in understandings of work processes based on how one's professional interest and contribution is focused and what (s)he finds important in his/her work. A pivotal question, therefore, is: to what extent should understandings of work process knowledge be congruent, and to what extent can they diverge from each other without disturbing the fluency of work practices? In order for the core processes of overall care to be perceived similarly by all the professional groups, strong leadership and coordination of collaboration are also needed.

\section{The realisation of interprofessional collaboration in the emergency unit}

In this project, interprofessional collaboration was approached as an ideal procedure, as defined by the behavioural sciences. In scholarly literature, interprofessionalism is seen as counterbalancing the fragmentation of science and professional practices (e.g. Bleakley et al. 2006). The biggest obstacles to the realisation of interprofessional collaboration have been found to be organisational in nature rather than clinical or related to the actors' know-how (Ramanujam and Rousseau 2006; Isoherranen 2012). In health care organisations, these kinds of obstacles include i) a hierarchical structure that prevents democratic action, particularly in stressful situations, ii) a deficient flow of information between professional groups at different levels of the hierarchy and iii) the divergent statuses and positions of professional groups, which makes dialogue between different professional groups difficult (Nembhard and Edmondson 2006). Furthermore, research has identified the following factors that promote interprofessionalism: opportunities for collegial support, an understanding of group members' roles and overall processes, and a comfortable work atmosphere (e.g. Collin, Paloniemi and Mecklin 2010). According to the insights of the INPROF project, these prerequisites for, and obstacles to, interprofessional collaboration are also present in the work of the emergency unit.

We found that the majority of medical emergency work in the unit studied here can be carried out most suitably via multi-professional collaboration. Interprofessional collaboration and boundarycrossing between professional groups (e.g. Akkerman and Bakker 2011; Fenwick 2006) seem to occur in the ideal form described above both in the most fast-paced and challenging clinical situations (e.g. with an emergency patient in the trauma room) and in certain smaller manifestations, such as in mutual care planning or the treatment of particular patient groups (Collin et al. 2012). Successful medical emergency work does not seem to presuppose continuous joint planning in line with the ideals of interprofessionalism and shared expertise. Therefore, maintaining interprofessional practice as such is not essential but, rather, it is important to find those points of collaboration where more interprofessionalism would improve the overall functionality of the work.

Why, then, does interprofessional collaboration seem to function particularly in the most challenging clinical situations? Several previous studies (e.g. Copnell et al. 2003; Krogstad, Hofoss and Hjortdal 2004) have, in accordance with the findings of the INPROF project, argued that different professional groups have divergent understandings of each other's roles and of what is expected of individuals acting in different roles. Apparently, in mundane and non-urgent emergency work, there is no profound, situational demand for interprofessionalism; here, multi-professional collaboration is adequate. In real emergency situations and other demanding or problematic patient cases, however, professional experience and know-how are perhaps more valuable than professional hierarchies at certain points of the treatment process. In addition, training for exceptional situations is arranged regularly, indicating that professionals come together regularly to discuss and learn about each other's roles. Actions in challenging care situations thus appear, at least outwardly, to be interprofessional and mutually shared. 
Interprofessional collaboration is not only a question of sharing and combining know-how, competence and expertise for organisational processes as a whole (what one does). In addition, the nature of professional collaboration and work cultures has a role: to exercise and develop interprofessionalism, it is important that collaboration occurs via humane interaction in a group (how one acts). Here, leadership and management play a crucial role. For example, the development of emergency work as a whole demands greater collaboration between chief doctors and nurses. Although multi-professional collaboration appears to be the most adequate form of collaboration in mundane emergency work, stronger interprofessionalism in leadership and management would perhaps also become manifest in the everyday work of all staff members due to improvements to the consistency of instructions, work practices and the flow of information aspects which this project has found to be central challenges within emergency health care at present. Such overall consistency in functions and guidelines would facilitate the interaction of professionals in hectic care situations.

The different cultures and professional identities within the various professional groups also offer fruitful perspectives for investigating collaboration. Despite the professional groups' shared ultimate aim of efficient patient care, the core identities of different professional practitioners seem to rest upon dissimilar values, as linked with the historical formation of these roles (for example, the importance, for doctors, of finding a medical solution and, for nurses, of delivering comprehensive patient care). The core qualities of professional identities are solid, but there are also aspects to these roles that are ever-changing and are (re)negotiated situationally, relative to other actors in the work community or in the organisation more broadly (Paloniemi et al. forthcoming). An example of the social nature of professional identity is the introduction of the modified chief duty nurse system in the emergency unit, as discussed above. The nursing community was not used to hybrid roles with changing power positions' (basic nursing vs. shift-specific leading of nursing), which manifested itself as constant negotiations and tensions on the new role in the everyday work.

The organisational change studied here also evidenced how important it is to make sure that the whole staff can participate in the change process, especially at its most critical points (Valleala et al. in press). Moreover, a new system must be monitored and controlled before it can be applied in other contexts. In the case of the chief duty nurse system, collaboration with chief doctors was not utilised sufficiently; the system was planned and put into practice mostly from the perspective of the nurses' work. A stronger emphasis on interprofessional collaboration might have aided the implementation of the change process and change-related learning.

In addition to the obstacles presented above, power relations (official and unofficial) are one of the biggest barriers to interprofessional collaboration. For instance, if one group of professionals has more power than the other groups in the work community, it is clear that collaboration cannot materialise in an ideal and democratic way (see Collin et al. 2011). Moreover, traditional power structures do not sit well with the ideas of work process knowledge and interprofessionalism that emphasise e.g. dynamicity and low professional boundaries.

\section{Conclusions}

Central to work process knowledge is the idea of perceiving the sum total of the work of a unit from the genuine viewpoint of different actors (Järvensivu 2007). This is best actualised in interprofessional collaboration, where perceptions, experience and know-how of different professionals are obviously combined (Housley 2003), as opposed to multi-professional collaboration, where professionals exchange information but still adhere strongly to their own professional groups. Interprofessional collaboration does not exist, nor is it needed, in every phase 
of medical emergency work; instead, it is embedded partially and situationally in different contexts, structures and practices. Thus, the arrangement of other opportunities to become acquainted with one's colleagues would be beneficial to an emergency unit - for example, workshops, where different perceptions and values can be discussed openly.

More interprofessional collaboration would be required particularly in leadership and management, to improve i) the coordination of work as a whole, and ii) the implementation of organisational changes and new or modified professional roles. In addition, an interprofessional development plan for workplaces - entailing commitment from all the professional groups - is necessary here (Viinikainen et al. 2012). Taking our findings into account, we also agree with Kilminster and Zukas (2007) in arguing that interprofessional collaboration needs to be included in curricula for medical education. Current obstacles to interprofessional collaboration appear in particular to be: i) diverging professional values and core identities, and ii) power relations that create inequality. Ultimately, the nature of collaborative situations varies depending on the individuals involved - our research showed that interprofessionalism sometimes manifests itself surprisingly amid multiprofessional work when particular professionals are working together. In general, it seems important to ask: what kinds of collaborative situations in medical emergency work must be interprofessional and what kinds do not need to be? How can a model be built that promotes efficient decision-making in situations where there is scarce time for thorough discussion (Rekola, Isoherranen and Koponen 2005)?

The INPROF researchers participated in the emergency unit's developmental actions, especially with regard to the modified chief duty nurse system and leadership and management. The findings of the project were brought to the unit as points to be considered, and they were taken into account in the unit's developmental actions. Based on our findings and experiences, putting even moderate developmental efforts into action requires major changes in attitudes in order to promote collaboration, negotiation and the realisation of possibilities; in other words, a common will needs to be fostered across all professional groups in circumstances strained by divergent administrations, cultural traditions and the challenging nature of the work. Development can usually be executed in small measures at most, and major changes often take years or even decades. However, the complexity of a work context should not be seen as an insurmountable barrier; developmental efforts should be pursued relentlessly when developmental needs are detected, as evidenced above.

\section{Suggestions for further research}

In practice, the commitment of an individual professional to collaboration and development is defined ultimately by what (s)he considers most important for his or her own work. At least in the INPROF project, nurses were more committed to, and active in, developing collaboration than doctors. This observation can be seen in many of the areas and perspectives examined in the project. Our knowledge and understanding of the point of view of doctors is still too narrow here, and thus warrants further investigation.

Within the project, we noted that when the development of the emergency unit's action was examined generally at the level of overall action, it often appeared unproblematic. When, instead, developmental actions were scrutinised more closely - from the perspectives of the staff and managers, for example - the situation was revealed to be more multifaceted (Valleala et al. in press). Hence, we recommend a mixed-methods approach (e.g. quantitative surveys and qualitative scrutiny of action) to attain a rich understanding of the context and build a solid, research-based foundation for organisational development.

As has been addressed in numerous studies of workplace learning (e.g. Collin et al. 2008; Hodkinson, Biesta and James 2008; Paloniemi and Collin 2010b), in order to understand work 
processes, the conditions and constraints within collaboration, and/or the development of expertise, processes at the individual and social levels must be seen as intertwined and, therefore, approached simultaneously and equivalently. This is a challenging task, conceptually and methodologically. In this research project, we have been able to show the importance of interweaving the individual and the collective, especially in developmental efforts. In this way, an individual employee may increase his/her understanding of authority in different decision-making situations, which will help the person to position him/herself as a meaningful member of the work community. This approach can aid different professional groups in understanding the roles, hopes and wishes of the other groups better. Based on our findings, there is a space for distributed expertise to emerge and be promoted in emergency work: every person has a defined role, but each knows and respects the roles of the other staff members. As such, we suggest that work identities amid interprofessional collaboration and learning need to be taken into the heart of professional development and education more consistently and extensively. In addition, the findings of this research project have shown that the focus here should be placed upon on various local and context-specific studies, in order, eventually, for a comprehensive model of shared expertise to be generated.

\section{Limitations of the study}

This research project investigated the collaboration of professionals in one hospital emergency unit. Qualitative research per se does not allow generalisations (Patton 2002), nor were such generalisations pursued to begin with in this study. The findings of this project can be utilised, however, in researching and developing action in similar work contexts. Further, different methodological choices, such as quantitative surveys or extensive interviews with staff members, would have yielded different types of data. Both researcher triangulation and methodological triangulation, in addition to frequent discussions with the emergency unit staff, were utilised to validate the data, but we acknowledge that a degree of subjectivity is always present in the interpretations of qualitative research.

Acknowledgement: This paper has received funding from the Finnish Work Environment Fund (project number 109295). 


\section{References}

Akkerman, S.F., and A. Bakker. 2011. "Boundary Crossing and Boundary Objects." Review of Educational Research 81 (2): 132-169.

Baker, D.P., R. Day, and E. Salas. 2006. "Teamwork as essential component of high-reliability organization.” Health Services Research 41 (4) (Part II): 1577-1598.

Bess, K.D., D.D. Perkins, D.G. Cooper, and D.L. Jones. 2011. "A heuristic framework for understanding the role of participatory decision making in community-based non-profits." American Journal of Community Psychology 47 (3/4): 236-252.

Bleakley, A., J. Boyden, A. Hobbs, L. Walsh, and J. Allard. 2006. "Improving teamwork climate in operating theatres: The shift from multi-professionalism to interprofessionalism." Journal of Interprofessional Care 20 (5): 461-470.

Boreham, N. 2004. "Orienting the work-cased curriculum towards work process knowledge: a rationale and a German case study." Studies in Continuing Education 26 (2): 209-227.

Braun, V., and V. Clarke. 2006. "Using thematic analysis in psychology." Qualitative Research in Psychology 3 (2): 77-101.

Collin, K., S. Paloniemi, and J-P. Mecklin. 2010. "Promoting inter-professional teamwork and learning - the case of a surgical operating theatre." Journal of Education and Work 23 (1): 43-63.

Collin, K., S. Paloniemi, A. Virtanen, and A. Eteläpelto. 2008. "Constraints and challenges on learning and construction of identities at work." Vocations and Learning: Studies in Vocational and Professional Education 1 (3): 191-210.

Collin, K., T. Sintonen, S. Paloniemi, and T. Auvinen. 2011. "Work, power and learning in a risk filled occupation." Management Learning 42 (3): 301-318.

Collin, K., U.M. Valleala, S. Herranen, and S. Paloniemi. 2012. "Ways of interprofessional collaboration and learning in emergency work." Studies in Continuing Education 34 (3): 281-300.

Copnell, B., L. Johnston, D. Harrison, A. Wilson, A. Robson, C. Mulcahy, L. Ramudu, G. McDonnell, and C. Best. 2003. "Doctors' and nurses' perceptions on interdisciplinary collaboration in the NICU, and the impact of a neonatal nurse practitioner model of practice." Journal of Clinical Nursing 13 (1): 105-113.

D’Amour, D., M. Ferrada-Videla, L. San Martín-Rodríguez, and M-D. Beaulieu. 2005. "The conceptual basis for interprofessional collaboration: Core concepts and theoretical frameworks." Journal of Interprofessional Care 19 (2): 116-131.

Fenwick, T. 2006. "Escaping/Becoming Subjects: Learning to work the boundaries in boundaryless work." In Work, Subjectivity and Learning. Understanding Learning through Working Life, ed. S. Billett, T. Fenwick and M. Somerville, 21-36. Dordrecht: Springer.

Gordon, T., P. Hynninen, E. Lahelma, T. Metso, T. Palmu, and T. Tolonen. 2006. "Collective ethnography, joint experiences and individual pathways." Nordisk Pedagogik [Nordic Studies in Education] 26 (1): 3-15.

Hammersley, M., and P. Atkinson. 2007. Ethnography: Principles in Practice. London: Taylor \& Francis.

Hodkinson, P., G.J.J. Biesta, and D. James. 2008. "Understanding learning culturally: Overcoming the dualism between social and individual views of learning." Vocations and Learning: Studies in Vocational and Professional Education 1 (1): 27-47.

Housley, W. 2003. Interaction in Multidisciplinary Teams. Aldershot: Ashgate. 
Isoherranen, K. 2012. "Uhka vai mahdollisuus - moniammatillista yhteistyötä kehittämässä [A threat or a possibility - developing interprofessional collaboration]." $\mathrm{PhD}$ diss., University of Helsinki.

Jeffrey, B., and G. Troman. 2004. "Time for ethnography.” British Education Research Journal 30 (4): 535-548.

Järvensivu, A. 2007. "Työprosessitieto: avain monitaitoisuuteen [Work process knowledge: a key to versatility]." Tampere: Tampere University Press.

Kilminster, S., and M. Zukas. 2007. "Shifting professional boundaries through interprofessional education: a case of wishful thinking?" Paper presented at the RWL5 Conference. Cape Town, Republic of South Africa, December 2-5.

Krogstad, U., D. Hofoss, and P. Hjortdal. 2004. "Doctor and nurse perception of inter-professional co-operation in hospitals." International Journal for Quality Health Care 16 (6): 491-497.

Lemieux-Charles, L., and W. McGuire. 2006. "What do we know about health care team effectiveness?: a review of the literature." Medical Care Research and Review 63 (3): 1-38.

Lingard, L., S. Espin, C. Evans, and L. Hawryluck. 2004. "The rules of the game: interprofessional collaboration on the intensive care unit team." Critical Care 8 (6): 403-408.

López, S. P., J. M. Peón, and C. J. Ordás. 2006. "Human resource management as a determining factor in organizational learning." Management Learning 37 (2): 215-239.

McCallin, A. 2001. "Interdisciplinary Practice - A Matter of Teamwork: an integrated literature review." Journal of Clinical Nursing 10 (4): 419-428.

Nembhard, I. M., and A. Edmondson. 2006. "Making it safe: The effects of leader inclusiveness and professional status on psychological safety and improvement efforts in health care teams." Journal of Organizational Behavior 27 (7): 941-966.

Paloniemi, S., and K. Collin. 2010a. "Mitä ihmettä on kollektiivinen etnografia? Kokemuksia organisaatiotutkimuksesta [What is collective ethnography?]." In Ikkunoita tutkimusmetodeihin [Windows towards Research Methods], ed. R. Valli, 204-221. Jyväskylä: PS-kustannus.

Paloniemi, S., and K. Collin. 2010b. "Workplace learning and work-related identity construction in a clinical setting.” In Handbook of Lifelong Learning Developments, ed. M. M. Caltone, 141-161. New York: Nova.

Paloniemi, S., K. Collin, U.M. Valleala, and S. Herranen. Forthcoming. "Professional development amid changing work roles: a perspective of professional identity negotiations." Submitted to International Journal of Training and Development.

Patton, M. Q. 2002. Qualitative Research and Evaluation Methods. Thousand Oaks, CA: SAGE.

Pollard, K., D. Sellman, and B. Senior. 2005. "The need for interprofessional working." In Interprofessional Working in Health and Social Care: Professional Perspectives, ed. G. Barrett, D. Sellman, and J. Thomas, 7-17. Basingstoke: Palgrave Macmillan.

Pullon, S. 2008. "Competence, respect and trust: key features of successful interprofessional nursedoctor relationships." Journal of Interprofessional Care 22 (2): 133-147.

Ramanujam, R., and D.M. Rousseau. 2006. "The challenges are organizational, not just clinical." Journal of Organizational Behavior 27 (7): 811-827.

Rekola, L., K. Isoherranen, and L. Koponen. 2005. "Moniammatillinen yhteistyö päivystyspoliklinikalla [Interprofessional collaboration in an emergency clinic]." Tutkiva Hoitotyö [Nursing Evidence] 3: 16-21.

Sigaud, L. 2008. "A collective ethnographer: fieldwork experience in the Brazilian Northeast." Social Science Information 47 (1): 71-97. 
1

2

3

4

5

6

7

8

9

Valleala, U.M., S. Herranen, K. Collin, and S. Paloniemi. In press. "Fostering learning opportunities through employee participation amid organizational change." Vocations and Learning: Studies in Vocational and Professional Education. DOI: 10.1007/s12186-014-9121-0.

Viinikainen, S., A. Solonen, M. Manninen, and P. Pyhälä-Liljeström. 2012. "Tukeeko moniammatillisuus hoitotyön johtamista päivystysalueella? [Does interprofessionalism support the management and leadership of nursing in an emergency unit?]" In Yhteistyö ja moniammatillisuus akuuttihoidossa. Ryhmätoiminnan ja moniammatillisen yhteistyön kehittäminen sairaalan päivystysalueella [Collaboration and interprofessionalism in acute care. Developing teamwork and interprofessional collaboration in a hospital emergency unit], ed. K. Collin, S. Paloniemi, and S. Herranen. Jyväskylä: University of Jyväskylä Printing House. Available online: https://jyx.jyu.fi/dspace/bitstream/handle/123456789/37906/978-951-39-4758-3.pdf?sequence=1. Wenger, E. 1998. Communities of practice. Learning, meaning and identity. Cambridge: Cambridge University Press.

Woods, P., M. Boyle, B. Jeffrey, and G. Troman. 2000. "Research team in ethnography." International Journal of Qualitative Studies in Education 13 (1): 85-98. 
Figure 1. Themes of collaboration in emergency work.

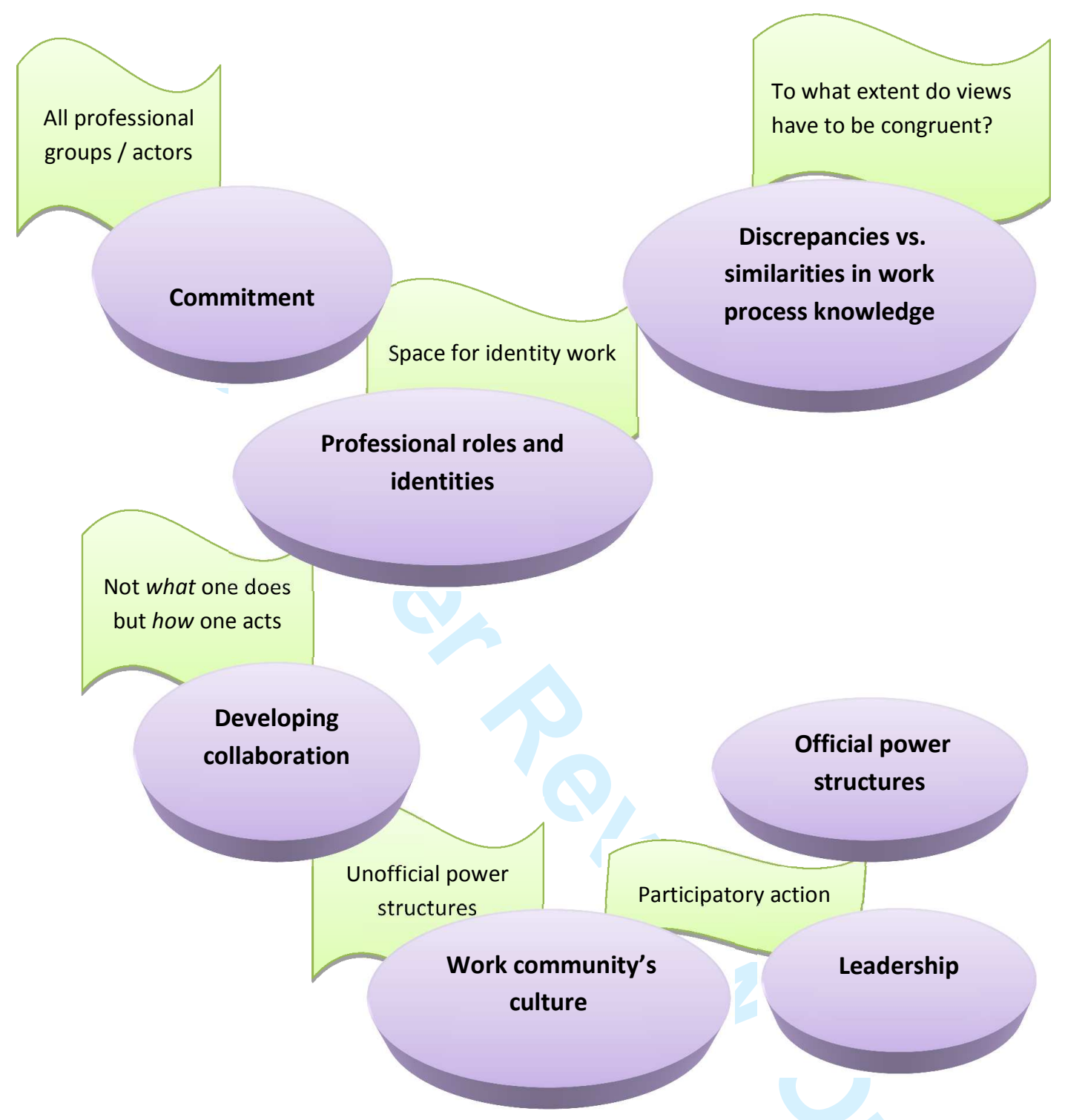


Table 1. Sub-studies in the INPROF project.

\begin{tabular}{|c|c|c|}
\hline Phenomenon & Data & Why? \\
\hline $\begin{array}{l}\text { Teamwork and } \\
\text { interprofessional } \\
\text { collaboration in emergency } \\
\text { work } \\
\text { Collin et al. } 2012 \text {. }\end{array}$ & $\begin{array}{l}\text { Observations ( } 85 \text { hours), } \\
\text { interviews }(n=11)\end{array}$ & $\begin{array}{l}\text { To get acquainted with teamwork } \\
\text { processes and interprofessional } \\
\text { collaboration in the unit. }\end{array}$ \\
\hline Ward rounds on the EIW & $\begin{array}{l}\text { Observations ( } 10 \text { hours), } \\
\text { interviews }(\mathrm{n}=8)\end{array}$ & $\begin{array}{l}\text { Rounds are an essential means of } \\
\text { collaboration, while also being a } \\
\text { partially problematic area. }\end{array}$ \\
\hline $\begin{array}{l}\text { Participation opportunities } \\
\text { amid organizational } \\
\text { change } \\
\text { Valleala et al. in press. }\end{array}$ & $\begin{array}{l}\text { Audio-recordings and } \\
\text { observations in meetings } \\
\text { ( } 20 \text { hours), field interviews } \\
\text { with } 10 \text { chief duty nurses } \\
\text { and six care teams, } \\
\text { interview with the head } \\
\text { nurse, observations on the } \\
\text { work of chief duty nurses } \\
\text { ( } 22 \text { hours). }\end{array}$ & $\begin{array}{l}\text { Due to rearrangements in } \\
\text { regional emergency care, a } \\
\text { substantial increase in the unit's } \\
\text { patient volume was anticipated; } \\
\text { the response was to change } \\
\text { several action models, e.g., the } \\
\text { chief duty nurse system. }\end{array}$ \\
\hline $\begin{array}{l}\text { The identity negotiations } \\
\text { and professional agency of } \\
\text { a changing professional } \\
\text { role (chief duty nurse) in } \\
\text { the work community } \\
\text { Paloniemi et al. } \\
\text { forthcoming. }\end{array}$ & $\begin{array}{l}\text { A focus group interview } \\
\text { with five chief duty nurses, } \\
\text { interviews with two head } \\
\text { nurses, field interviews } \\
\text { with } 10 \text { chief duty nurses } \\
\text { and six care teams, } \\
\text { observations on the work } \\
\text { of chief duty nurses ( } 22 \\
\text { hours). }\end{array}$ & $\begin{array}{l}\text { The role of chief duty nurse is } \\
\text { rather unique, both nationally } \\
\text { and internationally, an area upon } \\
\text { which little previous research has } \\
\text { been done. }\end{array}$ \\
\hline
\end{tabular}

